\title{
Lung deposition of nebulised pentamidine in children
}

\author{
M J O'Doherty, S H L Thomas, D Gibb, C J Page, C Harrington, C Duggan, \\ T O Nunan, N T Bateman
}

\begin{abstract}
Background Nebulised pentamidine is effective for preventing Pneumocystis carinii pneumonia in adults with acquired immunodeficiency syndrome. The nebuliser dose required to produce equivalent lung concentrations of pentamidine in children is unknown. This study was performed to measure pulmonary pentamidine deposition in children and to relate this to age, ventilation pattern, and body size.

Methods Nebulised pentamidine $(50 \mathrm{mg}$ in $6 \mathrm{ml}$ saline) was administered to 12 children (including one with lymphocytic interstitial pneumonitis) and to six adults with human immunodeficiency virus infection using a Respirgard II nebuliser. Technetium-99m labelled colloidal human serum albumin was used as an indirect marker for pentamidine and deposition in the lungs was detected by a gamma camera.
\end{abstract}

Results Absolute deposition of pentamidine was not related to age, height, weight, spirometry, or ventilation characteristics. Deposition, as a mean (SD) percentage of nebuliser output, was similar in children aged 8-11 years $(5 \cdot 5(2 \cdot 4) \%)$, teenagers aged 12-15 years $(7 \cdot 2(2 \cdot 2) \%)$ and adults $(7 \cdot 1(2 \cdot 6) \%)$. Aerosol concentration within the lungs (\% nebuliser output deposited/predicted total lung capacity) was therefore higher in children $(1.9(1.5) \% / 1)$ and teenagers $(1.9(0.7) \% / 1)$ than in adults $(1.0(0.7 \%) / 1)$, and was negatively correlated with height $(r=-0.69)$ and weight $(r=-0.50)$. Deposition of aerosol in the region of the large central airways was particularly marked in children. Small reductions in forced expiratory volume in one second and forced vital capacity after treatment did not differ significantly between adults and children and visual analogue scores of subjective adverse effects did not vary with age.

Conclusions These results suggest that children probably require lower nebuliser pentamidine doses to produce lung pentamidine concentrations equivalent to those found to be effective for preventing $P$ carinii pneumonia in adults using the Respirgard II nebuliser.

(Thorax 1993;48:220-226)
Nebulised drugs are often administered to children although little is known about the amount of drug reaching the lungs in this age group. For bronchodilators this is not an important problem as adequate drug delivery can be inferred from their rapid and easily measurable effects on lung function. ${ }^{1}$ For drugs which act at the site of deposition there is no simple way of measuring adequate drug delivery, and direct measurement is necessary to ensure this is adequate.

Nebulised pentamidine is an example of a treatment for which measurement of pulmonary drug deposition would be useful. It is used as prophylaxis against Pneumocystis carinii pneumonia in patients with human immunodeficiency virus (HIV) infection and low CD4 cell counts and as suppressive therapy following $P$ carinii pneumonia. Controlled clinical trials in adults have proved the efficacy of inhaled pentamidine in a dose of $300 \mathrm{mg}$ given once monthly via a Respirgard II nebuliser, ${ }^{23}$ and in a dose of 60 mg given every two weeks via a Fisoneb ultrasonic nebuliser after an initial loading regimen. ${ }^{4}$ Inhaled prophylaxis has become popular in adults as it avoids the systemic adverse effects common during long term oral suppressive therapy. Prophylactic regimens are also needed in children with HIV infection and the acquired immunodeficiency syndrome (AIDS) when allergy or haematological intolerance to cotrimoxazole and dapsone occurs. If quantities of pentamidine comparable to adults could be delivered to the lungs of these children, it is reasonable to assume that similar benefit would be obtained.

The amount of nebulised aerosol reaching the lungs of children has been little studied and there are several reasons to believe that it may differ from adults. These include differences in lung volumes, airway geometry, and the frequency and pattern of breathing and, most importantly, compliance with treatment which is a particular problem in the very young. Some of these factors are expected to have opposite effects on lung deposition. It is not therefore possible either to predict the amount of pentamidine deposited in the lungs of children, or the dose of nebulised pentamidine that should be used for therapy or prophylaxis.

In this study we have measured the lung deposition of $50 \mathrm{mg}$ nebulised pentamidine given via the Respirgard II nebuliser in a 
small group of children with HIV infection, and compared the results with those obtained in adults using identical inhalation and measurement techniques. The aims were to examine differences in deposition pattern between adults and children and to relate these to body size and lung function. The results could be used to determine the dose of pentamidine in children at risk of developing $P$ carinii pneumonia.

\section{Methods}

Pulmonary pentamidine deposition was measured in 18 male HIV antibody positive patients, 12 children and six adults. Informed consent was obtained from the patient or his parents before the study which was approved by the Ethics Committees of West Lambeth Health District and Great Ormond Street Hospital.

Each patient attended for the study on a single occasion. Their medical details, height, and weight were recorded. After a period of relaxation, respiratory minute volume was measured and the respiratory rate counted over a two minute period while the subject breathed through a mouthpiece attached to a Wright spirometer (Siemens) while seated. Simple spirometric measures of lung function-forced expiratory volume in one second $\left(\mathrm{FEV}_{1}\right)$, forced vital capacity (FVC), peak expiratory flow (PEF)-were performed before and after $2.5 \mathrm{mg}$ nebulised salbutamol was administered to prevent pentamidine induced bronchoconstriction. Spirometry was repeated after pentamidine inhalation. The tissue attenuation required for the calculation of absolute deposition was measured by performing an anteroposterior transmission scan of the chest using a $47 \mathrm{~cm}$ diameter cobalt- 57 flood source and a large field of view gamma camera with a high sensitivity collimator as previously described. ${ }^{5}$ Posterior xenon-133 equilibrium scans were performed to define the lung outline (using the $20 \%$ maximum count contour) and to divide the lung into upper, middle, and lower regions (by dividing the lung vertically into three parts of equal height), and into central (defined as a rectangle over the middle third of the medial border of the lung and extending half way across the lung) and peripheral regions (remainder of the lung).

The method of measuring pentamidine deposition has been described in detail elsewhere. ${ }^{67}$ A Respirgard II nebuliser (Marquest) was loaded with a solution consisting of $50 \mathrm{mg}$ pentamidine and $37 \mathrm{MBq}$ $(16 \mu \mathrm{g} / \mathrm{ml})$ technetium-99m labelled colloidal human serum albumin ${ }^{99 \mathrm{~m}} \mathrm{Tc}-\mathrm{HSA}$, Venticoll) in a total volume of $6 \mathrm{ml}$. The addition of the ${ }^{99 \mathrm{~m}} \mathrm{Tc}-\mathrm{HSA}$ marker does not affect the particle size or mass output of this nebuliser and is distributed in the aerosol cloud in a similar manner to pentamidine. ${ }^{89}$ Aerosol was produced by driving the nebuliser with compressed air $(8 \mathrm{l} / \mathrm{min})$ from an AFP Medical air compressor. The patients remained seated with their backs resting against the gamma camera and breathed normally from the nebuliser mouthpiece for the 40 minute period of aerosol inhalation while dynamic posteroanterior scans of the lungs were taken in 60 second counting frames to assess dynamic aerosol deposition. On completion of inhalation further static scans were taken of the lungs (anterior and posterior views), abdomen (anterior and posterior views), oropharynx (right lateral view), and inhalation apparatus using an acquisition time of 100 seconds. Activity contained within the nebuliser unit was measured before and after nebulisation using the gamma camera and an ionisation chamber.

Absolute pulmonary deposition was calculated from the activity detected within the lungs using corrections derived from the lung transmission studies as previously described. ${ }^{5}$ The ratio of counts detected with the subject seated between the flood source and the camera (I) and counts detected without the subject between the flood source and the camera $\left(\mathrm{I}_{0}\right)$ is related to the broad beam tissue attenuation $(\mu)$ and the tissue depth $(x)$ by the following formula ${ }^{10}$ :

$$
\mathrm{I} / \mathrm{I}_{0}=\mathrm{e}^{-\mu x}
$$

Measured geometric mean lung counts $(\mathrm{Gm})$, corrected using this formula, can be related to the initial nebuliser activity if the camera sensitivity is known. This was obtained by placing a thin sheet of polythene over the camera face. On top of this was placed a $30 \mathrm{~cm}$ diameter piece of absorbent paper soaked with technetium-99m of known activity (measured in $\mathrm{MBq}$ ). The counts detected by the camera (cps) could then be related to the technetium- $99 \mathrm{~m}$ activity to derive a camera sensitivity factor $(\mathrm{cps} / \mathrm{MBq}){ }^{11}$ Intrapulmonary technetium$99 \mathrm{~m}$ deposition can thus be calculated using the formula: ${ }^{12}$

\section{Deposition (\%) $=$}

Geometric mean lung counts $\times \mathrm{e}^{\mathrm{v} \times 2 \mathrm{2l}}$

Sensitivity factor $\times$ initial nebuliser activity $\times 100$

The weight of drug deposited was calculated by multiplying this value by the nebuliser pentamidine dose. The aerosol concentration in the lungs as a whole was estimated by dividing total lung deposition by the total lung capacity (TLC). TLC was estimated from the patient's height using standard tables. ${ }^{13}$ Regional lung volumes were calculated by dividing the xenon- 133 counts of the region in question by the total xenon-133 counts and multiplying by the predicted TLC. These regional lung volumes were used to calculate regional lung aerosol concentrations.

An aerosol deposition ratio was calculated as (central ${ }^{99 \mathrm{~m}} \mathrm{Tc}-\mathrm{HSA} /$ peripheral ${ }^{99 \mathrm{~m}} \mathrm{Tc}-\mathrm{HSA}$ )/ (central ${ }^{133} \mathrm{Xe} /$ peripheral ${ }^{133} \mathrm{Xe}$ ), where increasing values over unity indicate preferential central aerosol deposition, and the vertical distribution of pentamidine was estimated using a similar ratio comparing deposition in the upper and lower lung zones-

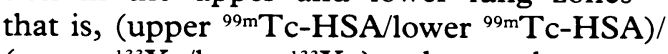
(upper ${ }^{133} \mathrm{Xe} /$ lower ${ }^{133} \mathrm{Xe}$ ), where values over 
one indicate preferential deposition of pentamidine in the upper lung. Regional lung aerosol deposition was assessed from the counts measured in the right lung only because this avoids activity which may be in the oesophagus or stomach. Dynamic deposition was measured using right lung data and corrected for tissue attenuation as above.

The adverse effects associated with each treatment were assessed using five separate visual analogue scales. Each of these consisted of a horizontal line, $6.5 \mathrm{~cm}$ in length, and at each end of this line the extremes of these symptoms were printed. The five scales used were: (1) no breathlessness-extreme breathlessness; (2) no nausea-severe nausea; (3) no burning-extreme burning; (4) pleasant taste-very unpleasant taste; and (5) the overall impression of the treatment, very pleasant-extremely unpleasant. Patients were asked to place a vertical line at the point on the scale that they thought was appropriate, and this position was expressed as a percentage of the line length.

Pulmonary deposition results were compared with a repeated measures analysis of variance (ANOVA) and related to age and measurements of body size and ventilation characteristics by simple regression. Visual analogue scale results were analysed using the non-parametric Wilcoxon signed rank test.

\section{Results}

To simplify the presentation of deposition data the patients were divided into three groups of equal size by age: children (8-11 years), teenagers (12-15 years), and adults $(>18$ years). Their details, including their ventilation characteristics and lung function after salbutamol, are shown in tables 1 and 2 . One of the children in the 12-15 year group had a diagnosis of lymphocytic interstitial pneumonitis with a chronic cough and chest radiographic changes consistent with this diagnosis, and one child in the 8-11 year

Table 1 Details of patients' previous respiratory problems and CDC classification

\begin{tabular}{|c|c|c|c|c|}
\hline Patient no & $\begin{array}{l}\text { Age } \\
\text { (years) }\end{array}$ & $H I V$ & $\begin{array}{l}\text { Chest radiographic } \\
\text { appearance }\end{array}$ & $\begin{array}{l}\text { Respiratory } \\
\text { history }\end{array}$ \\
\hline \multicolumn{5}{|l|}{ Children } \\
\hline 1 & 13 & Haemophilia & Normal & None \\
\hline 2 & 13 & Haemophilia & Normal & None \\
\hline 3 & 15 & Haemophilia & Normal & None \\
\hline 4 & 11 & Haemophilia & Normal & None \\
\hline 5 & 12 & Haemophilia & Normal & None \\
\hline 6 & 11 & Haemophilia & Normal & None \\
\hline 7 & 8 & Haemophilia & Normal & None \\
\hline 8 & 12 & Haemophilia & Normal & None \\
\hline 9 & 10 & Haemophilia & Normal & None \\
\hline 10 & 9 & Haemophilia & Normal & None \\
\hline 11 & 12 & Vertical infection & $\begin{array}{l}\text { Lymphocytic interstitial } \\
\text { pneumonitis }\end{array}$ & $\begin{array}{l}\text { Cough }+ \\
\text { dyspnoea }\end{array}$ \\
\hline 12 & 8 & Vertical infection & Normal & Mild asthma \\
\hline \multicolumn{5}{|l|}{ Adults } \\
\hline 1 & 32 & Haemophilia & Normal & None \\
\hline 2 & 53 & Haemophilia & Normal & None \\
\hline 3 & 39 & Haemophilia & Normal & None \\
\hline 4 & 34 & Haemophilia & Normal & None \\
\hline 5 & 33 & Haemophilia & Normal & None \\
\hline 6 & 35 & Haemophilia & Normal & None \\
\hline
\end{tabular}

group had mild asthma maintained on intermittent bronchodilators. Salbutamol inhalation did not have a significant effect on $\mathrm{FEV}_{1}$ or FVC, but both were reduced by a minor but significant amount following pentamidine inhalation $(p<0.05)$. These reductions were slightly larger in the children but the differences were not significant and there were no correlations with age, height, or weight.

Details of nebuliser output and pulmonary pentamidine deposition pattern are shown in table 3 and fig $1 \mathrm{~A}, \mathrm{~B}, \mathrm{C}$. Considerable variability in the output of the Respirgard II nebuliser was observed (coefficient of variation $22 \%$ ) and output in the teenagers was slightly larger than in the other two groups, although
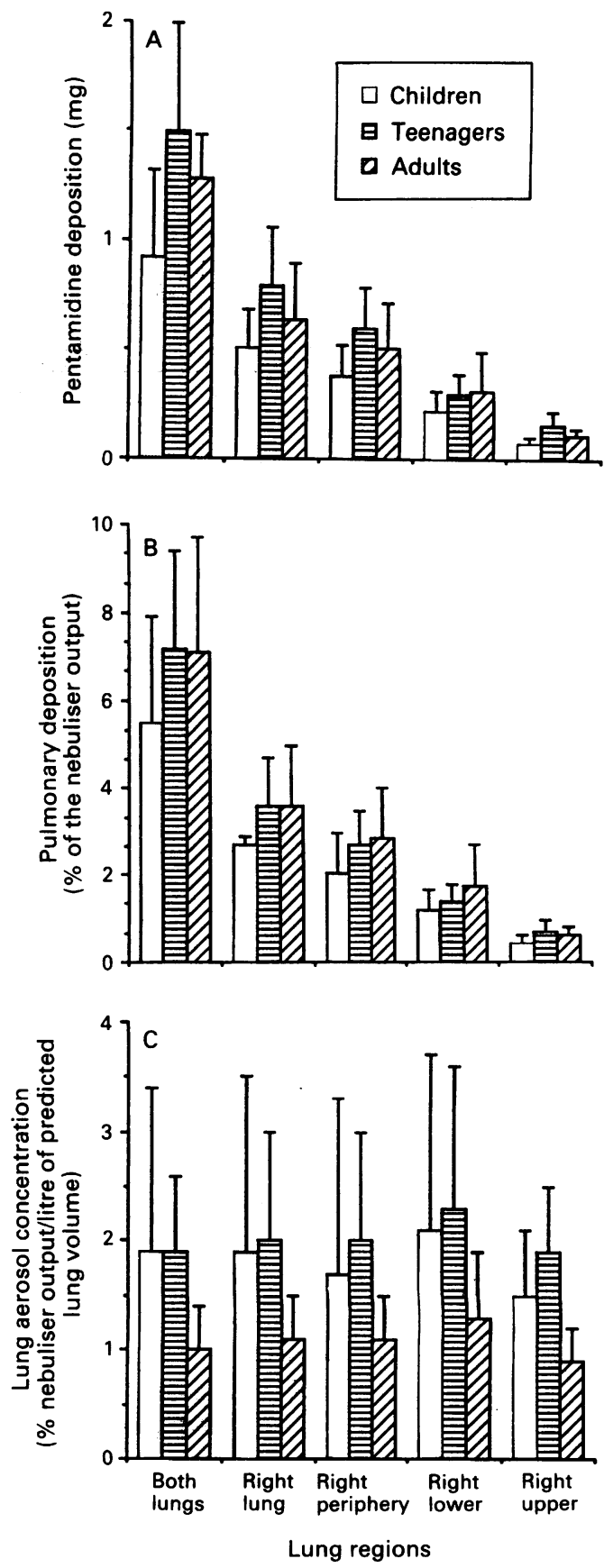

Figure 1 Pentamidine deposition within the lungs. A-Pentamidine deposition ( $\mathrm{mg}$ ) in both lungs, right lung, right peripheral lung, right upper third, and right lower third. $B-$ Pentamidine deposition in the lung regions corrected for the variation in nebuliser output. $C-$ Pentamidine deposition in the lung regions corrected for predicted lung volumes. 
Table 2 Mean (SD) morphometric data, ventilatory characteristics, and lung function in the 18 patients

\begin{tabular}{|c|c|c|c|}
\hline & $\begin{array}{l}\text { Children } \\
\text { (8-11 years) }\end{array}$ & $\begin{array}{l}\text { Teenagers } \\
\text { (12-15 years) }\end{array}$ & $\begin{array}{l}\text { Adults } \\
(\geqslant 18 \text { years })\end{array}$ \\
\hline $\mathbf{n}$ & 6 & 6 & 6 \\
\hline Weight (kg) & $35 \cdot 7(11 \cdot 6)$ & $43 \cdot 8(7 \cdot 9)^{\star}$ & $66 \cdot 2(12 \cdot 4)^{\star} \dagger$ \\
\hline Height $(\mathrm{cm})$ & $144(21)$ & $152(14)^{\star}$ & $176(10)^{\star} t$ \\
\hline Respiratory minute volume $(1 / \mathrm{min})$ & $6 \cdot 5(2 \cdot 0)$ & $6 \cdot 7(4 \cdot 3)$ & $5 \cdot 4(1 \cdot 2)$ \\
\hline Respiratory rate & $16(1)$ & $16(3)$ & $13(2) \dagger^{\star}$ \\
\hline Tidal volume & $412(103)$ & $400(211)$ & $397(49)$ \\
\hline \multirow{2}{*}{\multicolumn{4}{|c|}{$\begin{array}{l}\text { LUNG FUNCTION } \\
\text { After salbutamol }\end{array}$}} \\
\hline & & & \\
\hline FEV $_{1}$ & $1.65(0.83)$ & $2 \cdot 14(0 \cdot 74)$ & $4.08(1 \cdot 11)^{\star} \dagger$ \\
\hline FVC & $1.96(0.79)$ & $2 \cdot 33(0 \cdot 71)$ & $4 \cdot 27(1 \cdot 19)^{\star} \dagger$ \\
\hline PEF & $297(112)$ & $360(69)$ & $607(119)^{\star} \dagger$ \\
\hline \multicolumn{4}{|l|}{ After pentamidine } \\
\hline $\mathrm{FEV}_{1}$ & $1.50(0 \cdot 80)$ & $1.96(0.72)$ & $3.84(1 \cdot 15)^{\star} \dagger$ \\
\hline FVC & $1.80(0.73)$ & $2 \cdot 21(0.67)$ & $4 \cdot 18(1 \cdot 26)^{\star} t$ \\
\hline PEF & $303(106)$ & $379(99)$ & $606(132)^{\star} \dagger$ \\
\hline \multicolumn{4}{|l|}{ Change after pentamidine (\%) } \\
\hline FEV & $\begin{array}{l}-0 \cdot 16(0 \cdot 17) \\
(-8(12))\end{array}$ & $\begin{array}{l}-0.12(0.32) \\
(-8(13))\end{array}$ & $\begin{array}{l}-0 \cdot 11(0 \cdot 17) \\
(-6(10))\end{array}$ \\
\hline FVC & $\begin{array}{l}-0 \cdot 15(0 \cdot 25) \\
(-8(7))\end{array}$ & $\begin{array}{l}-0.18(0.39) \\
(-4(11))\end{array}$ & $\begin{array}{l}-0.24(0.42) \\
(-3(6))\end{array}$ \\
\hline PEF & $\begin{array}{l}6(13) \\
(3(5))\end{array}$ & $\begin{array}{l}19(39) \\
(4(10))\end{array}$ & $\begin{array}{l}-2(32) \\
(-1(7))\end{array}$ \\
\hline
\end{tabular}

FEV 1 -forced expiratory volume in one second; FVC-forced vital capacity; PEF-peak expiratory flow

${ }^{*} \mathrm{p}<0.05$ adults or teenagers $v$ children; $\mathrm{tp}<0.05$ adults $v$ teenagers.

the differences were not significant. To correct for this and to remove it as a source of variability, lung deposition was expressed as a percentage of the measured nebuliser output as well as in absolute terms (mg). Although absolute deposition values for both lungs and the peripheral and upper lung regions were significantly greater in the teenagers than in the children, these differences were not seen after the data had been corrected for differences in nebuliser output and a similar proportion of nebuliser output was deposited in each region in the three age groups (fig 1B).

To examine the factors which determine lung deposition, simple regression was performed with age, height, weight, $\mathrm{FEV}_{1}$, FVC, RMV (respiratory minute volume), tidal volume, and respiratory rate. No significant relationships were observed for total deposition or for deposition in any of the lung regions even when corrected for nebuliser output. When total deposition was corrected for predicted TLC (which includes lung dead space volume), the derived estimates of aerosol concentration within the lungs were

Table 3 Mean (SD) nebuliser output data, pulmonary pentamidine deposition ratios, and non-pulmonary pentamidine deposition

\begin{tabular}{|c|c|c|c|}
\hline & $\begin{array}{l}\text { Children } \\
\text { (8-11 years) }\end{array}$ & $\begin{array}{l}\text { Teenagers } \\
\text { (12-15 years) }\end{array}$ & $\begin{array}{l}\text { Adults } \\
(\geqslant 18 \text { years })\end{array}$ \\
\hline \multicolumn{4}{|l|}{ Nebuliser output } \\
\hline$\%$ & $38 \cdot 5(8 \cdot 0)$ & $45 \cdot 1(9 \cdot 6)$ & $36 \cdot 2(7 \cdot 3)$ \\
\hline mg & $19 \cdot 3(4 \cdot 0)$ & $22 \cdot 5(4 \cdot 8)$ & $18 \cdot 1(3 \cdot 6)$ \\
\hline \multicolumn{4}{|c|}{ Deposition ratios ( ${ }^{133} \mathrm{Xe}$ corrected) } \\
\hline $\begin{array}{l}\text { central/peripheral } \\
\text { upper/lower }\end{array}$ & $\begin{array}{l}1.92(0.64) \\
0.67(0.22)\end{array}$ & $\begin{array}{l}1.37(0.41) \\
0.95(0.29)^{\star}\end{array}$ & $\begin{array}{l}1.09(0.19)^{\star} \\
0.70(0.05)\end{array}$ \\
\hline \multicolumn{4}{|c|}{ Non-pulmonary deposition (cps) } \\
\hline Oropharynx & $23 \cdot 3(23 \cdot 4)$ & $21 \cdot 9(10 \cdot 4)$ & $23 \cdot 3(19 \cdot 2)$ \\
\hline Stomach & $13 \cdot 5(7 \cdot 3)$ & $11.9(10.6)$ & $23 \cdot 7(36 \cdot 6)$ \\
\hline Apparatus & $2704(1176)$ & $3345(1368)$ & $2618(628)$ \\
\hline Exhalation filter. & $1848(1363)$ & $2510(1157)$ & $1787(826)$ \\
\hline
\end{tabular}

${ }^{*} \mathrm{p}<0.05$ adults or teenagers $v$ children.

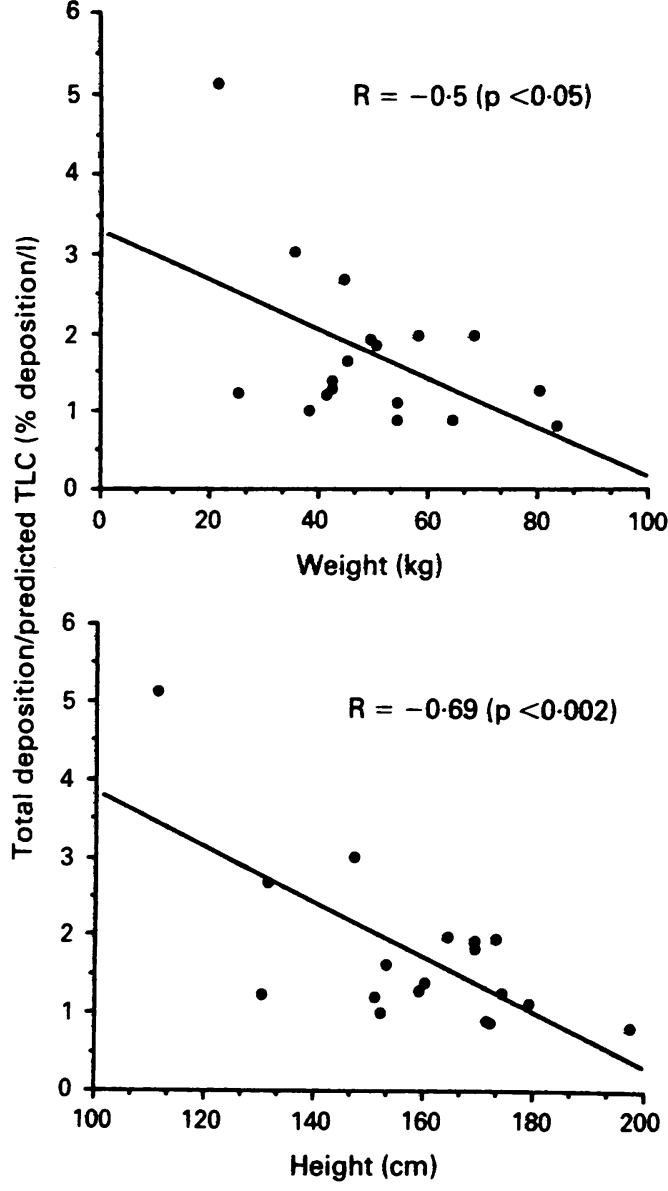

Figure 2 The relationship between pentamidine deposition per unit predicted lung volume and weight and height of the patient.
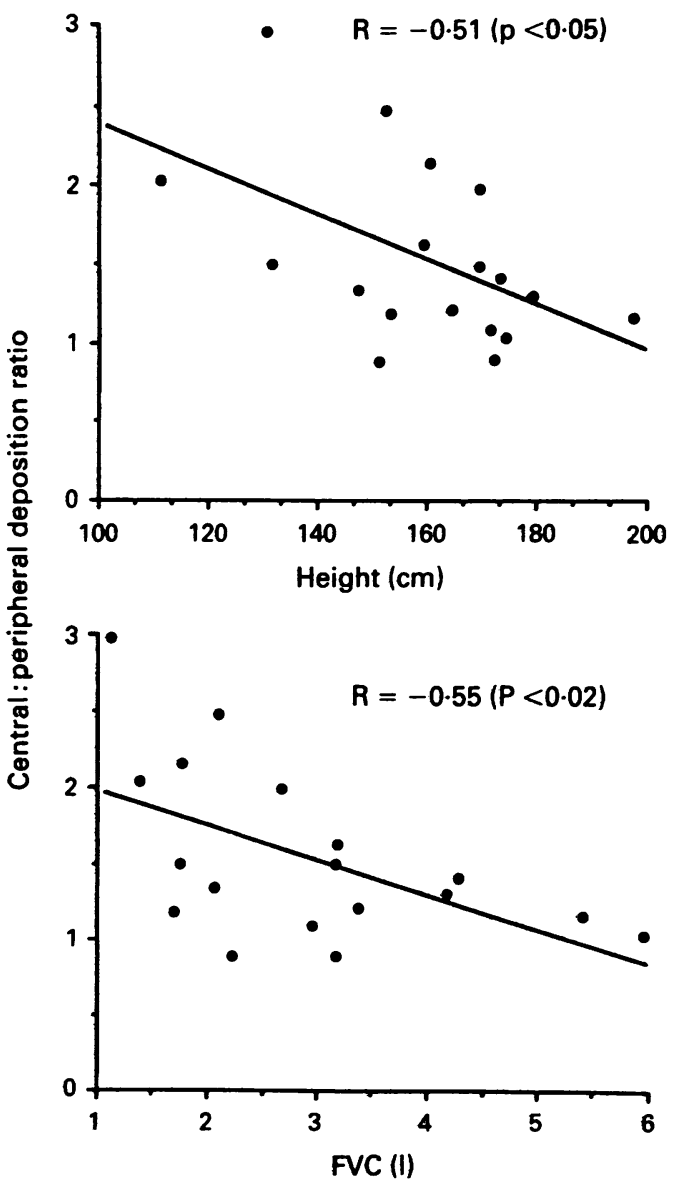

Figure 3 The relationship between the centrall peripheral deposition ratios and height and forced vital capacity (FVC). 
Table 4 Mean (SD) percentage subjective adverse effect scores associated with inhaled pentamidine measured on visual analogue scales

\begin{tabular}{llll}
\hline & $8-11$ years & $12-15$ years & $\geqslant 18$ years \\
\hline Breathless & $13(13)$ & $5(7)$ & $6(12)$ \\
Burning & $6(10)$ & $11(12)$ & $9(18)$ \\
Taste & $29(12)$ & $23(14)$ & $18(14)$ \\
Overall & $23(19)$ & $20(11)$ & $19(12)$ \\
\hline
\end{tabular}

All comparisons $\mathrm{p}>0.05$, Wilcoxon signed rank test

larger in the children and teenagers than in the adults (fig 1C) and there were significant negative correlations with height $(r=-0.69$, $\mathrm{p}<0.002)$ and weight $(r=-0.50, \mathrm{p}<0.05)$ (fig 2), but not age, FVC, RMV, or tidal volume. Aerosol concentration in the central region (an indication of the amount of aerosol in major central airways) was substantially higher in the smaller children and this value closely and negatively correlated with height $(r=-0.77, \mathrm{p}<0.001)$ and weight $(r=-0.66, \mathrm{p}<0.003)$.

Further information on the distribution of deposited aerosol within the lungs can be obtained from the central/peripheral and upper/lower lung deposition ratios. These have been corrected for regional lung volume using the same ratios derived from the xenon133 scan. The corrected central/peripheral deposition ratio was negatively correlated with age $(r=-0.54, \quad \mathrm{p}<0.03)$, height $(r=-0.51, \quad \mathrm{p}<0.05$, fig 3), weight $(r=-0.55, \mathrm{p}<0.02)$, and FVC $(r=-0.55$, $\mathrm{p}<0.02$, fig 3 ), confirming that the proportion of deposition in the central lung region was more marked in younger or smaller children or in those with reduced spirometric indices. The corrected upper/lower lung deposition ratio was not significantly related to any of these values.

The time course of pentamidine deposition within the lungs obtained from the dynamic lung scans performed during aerosol inhalation showed that deposition took between 31 and 39 minutes. No significant differences were observed between the three age groups and the time to $95 \%$ deposition was not related to height, weight, ventilation characteristics, or FVC.

This dose of pentamidine administered using the Respirgard II nebuliser was well tolerated by the patients and all were able to complete the inhalation. Adverse effect scores calculated from the visual analogue scales did not differ significantly between the three groups (table 4). Changes in lung function provoked by pentamidine inhalation did not correlate significantly with age or body proportions, either when expressed in absolute terms or as percentage changes. Deposition of pentamidine in extrapulmonary sites and in the nebuliser apparatus was very variable and did not differ significantly between the three patient groups (table 3 ).

\section{Discussion}

In this study we selected a $50 \mathrm{mg}$ dose of pentamidine dissolved in $6 \mathrm{ml}$ solution inhaled using a Respirgard II nebuliser and measured deposition using ${ }^{99 \mathrm{~m}} \mathrm{Tc}-\mathrm{HSA}$ as an indirect marker for pentamidine. This nebuliser was chosen because it is in common use for pentamidine inhalation, produces small sized particles, and is well tolerated. ${ }^{67}$ The pentamidine dose is lower than that used in clinical trials in adults with this nebuliser. ${ }^{2}{ }^{3}$ It was chosen because it is easier to inhale than higher doses and because we did not want to risk producing very high lung pentamidine concentrations in the smaller children. The high nebuliser solution volume was chosen because it increases delivery of pentamidine to the lungs and reduces local adverse effects. ${ }^{6}$ In the absence of a directly labelled pentamidine analogue, ${ }^{99 \mathrm{~m}} \mathrm{Tc}-\mathrm{HSA}$ appears to be the best marker currently available for measuring pentamidine deposition. ${ }^{89}$ The method of geometric correction is accurate to within a few percentage points in adults, ${ }^{514}$ and there is no reason to believe that the method is inaccurate in children.

The major finding of this study was that total pentamidine deposition in the lungs of children aged between eight and 15 years did not differ significantly from values obtained in adults in this study and in a previous report of 10 adults with and without previous $P$ carinii pneumonia. ${ }^{6}$ The one patient with lymphocytic interstitial pneumonitis had the lowest deposition for his age group $(0.8 \mathrm{mg}$ in the whole lung and $0.34 \mathrm{mg}$ in the right lung periphery, 12-15 year group) and this group of patients will require specific assessment of nebulised pentamidine deposition. Overall the concentration of pentamidine/l predicted TLC of the children was significantly higher than that achieved in adults and concentrations were particularly high in the central lung region. This may be because more aerosol is deposited in the central airways as a result of their smaller calibre in children. In spite of this, similar total quantities of aerosol were deposited in the peripheral lung of children and adults and, as with total deposition, the concentration of aerosol in peripheral lung was increased in the children. Furthermore, peripheral lung volume may have been overestimated in the children because it was was calculated from the TLC using xenon-133 counts; these do not take account of the anatomical dead space which forms a larger proportion of TLC in children. Concentrations of drug per unit volume may therefore be even higher in children than the estimates given here.

There are three major drawbacks to this study. Firstly, pulmonary aerosol deposition is highly variable between individuals. It is therefore desirable to make measurements on a large number of subjects to allow weaker relationships between total aerosol deposition and other factors such as age, height or FVC to be demonstrated or excluded with greater certainty. We studied as many children as we could, but accept that the small number involved means that some subtle differences between adults and children may have been missed. Secondly, we would have liked to 
measure TLC in each individual rather than estimating the value from the height. We were unable to do this because the apparatus available in our hospital was not designated for use by HIV antibody positive patients at the time of this study. Nevertheless we believe that our estimates are within $10 \%$ because only one of our subjects had an abnormal chest radiograph and chronic respiratory symptoms (with lymphocytic interstitial pneumonitis), and there is a close and predictable relationship between height and TLC under these circumstances with a standard deviation of approximately $10 \% .^{13}$ Thirdly, it would have been more accurate to measure ventilatory characteristics such as respiratory rate and minute volume while the subjects were inhaling the aerosol rather than beforehand. Measurement over a period before aerosol inhalation, while simpler, may have obscured relationships between ventilatory characteristics and aerosol deposition. Simultaneous measurement would require the use of a method which does not interfere with aerosol inhalation such as impedance plethysmography. This was impractical in the children.

The results of our study give a total lung deposition of $2.5 \%$ of the nebuliser dose compared with 3\% reported by Alderson et $a^{15}$ (for children between 7.5 and 14 years). Alderson et al found a close correlation between total pulmonary deposition and age, but they studied children aged from 1.5 to 17 years with cystic fibrosis. Our data do not exclude the possibility that total pulmonary aerosol deposition is reduced in children under eight years because none were studied. Unlike our study, the patients with cystic fibrosis inhaled via a facemask. Under these circumstances the quantity of aerosol reaching the lungs will depend in part on the amount of nasal breathing, ${ }^{16}$ which will vary with the age of the child. Furthermore, aerosol deposition is abnormal in patients with bronchiectasis who have more marked central deposition. ${ }^{1718}$ The quantitative results of the study by Alderson et al are derived from only 11 of the 18 children studied. No reason is given for excluding the other seven. If this was because of outlying values, it would explain why their results are so much more consistent than those of many studies of aerosol deposition in adults. Finally, we cannot estimate the concentration of aerosol deposition in the lungs of their patients with cystic fibrosis because TLC was not measured and, in these patients, estimates from their heights will not be accurate because of their abnormal lungs. It is possible that higher concentrations of aerosol were achieved in the smaller lungs of the children in spite of the positive relationship between age and total lung deposition.

Our study was not designed to establish the best method for pentamidine inhalation in children and alternative nebulisers may produce superior deposition or be better tolerated. Our results can only apply to the inhalation of aerosols produced by jet nebu- lisers driven by a comparable gas flow rate of $8 \mathrm{l} / \mathrm{min}$. Collis et al $^{19}$ speculated that once entrainment of air occurs, there is little difference between the amount of aerosol inspired between children and adults; this is consistent with our results (fig 1B). Use of an ultrasonic rather than a jet nebuliser may be more efficient in children because most of the aerosol is retained within the ultrasonic nebuliser unit until sampled from the mouthpiece; thus waste into the atmosphere may be reduced in children with small tidal volumes. Unfortunately many ultrasonic nebulisers put out large sized particles with consequent increases in central and upper airways deposition and local adverse effects. ${ }^{7}$

From the results of our study it is possible to estimate the dose of pentamidine required to produce similar lung concentrations in children to those found in adults. We propose that large children with heights above $160 \mathrm{~cm}$ should receive an adult dose of pentamidine $(300 \mathrm{mg}$ in $6 \mathrm{ml}$ ) and smaller children with heights between 130 and $160 \mathrm{~cm}$ should receive $150 \mathrm{mg}$ in $6 \mathrm{ml}$. Children smaller than $130 \mathrm{~cm}$ were not studied so no recommendation can be given. A third of an adult dose or less may be considered reasonable but studies in this age group are needed. These doses should produce similar lung concentrations of pentamidine to those of adults and therefore a similar success in the treatment of $P$ carinii pneumonia may be seen. Clinicians can use our measurements to adjust the dosing schedules in children to provide slightly higher lung concentrations if this is felt appropriate.

The prophylactic value and safety of nebulised pentamidine in children can only be proven by appropriately designed large scale clinical trials. We would suggest that the estimates of pulmonary pentamidine deposition presented here are taken into account in the design of such studies.

1 Blackhall MI, O'Donnell SR. A dose-response study of inhaled terbutaline administered via nebuhaler or nebuliser to asthmatic children. Eur $\mathcal{f}$ Respir Dis 1987;71: 96-101

2 Leoung GS, Feigal DW, Montgomery AB, Corkery K, Wardlaw L, Adams M, et al. Aerosolized pentamidine for prophylaxis against Pneumocystis carinii pneumonia. The San Francisco community prophylaxis trial. $N$ Engl f Med 1990;323:769-75.

3 Hirschel B, Lazzarin A, Chopard P, Opravil M, Furrer H$\mathrm{J}$, Rüttimann $\mathrm{S}$, et al. A controlled study of inhaled pentamidine for primary prevention of Pneumocystis carinii pneumonia. N Engl f Med 1991;324:1079-83.

4 Montaner JSG, Lawson LM, Gervais A, Hyland RH, Chan CK, Falutz JM, et al. Aerosol pentamidine for secondary prophylaxis of AIDS-related Pneumocystis carinii pneumonia. Ann Intern Med 1991;114:948-53.

5 Thomas SHL, O'Doherty MJ, Page CJ, Nunan TO Variability in the measurement of nebulized aerosol deposition in man. Clin Sci 1991;81:767-75.

6 O'Doherty M, Thomas SHL, Page C, Bradbeer CS, Nunan T, Bateman NT. Pulmonary deposition of nebulised pentamidine. The effect of nebuliser type, dose, lised pentamidine. The effect of nebuliser

7 Thomas SHL, O'Doherty MJ, Page CM, Nunan TO, Bateman NT. Which apparatus for inhaled pentamidine? A comparison of pulmonary deposition via eight nebulisers. Eur Respir f 1991;4:616-22.

8 Smaldone GC, Perry RJ, Deutsch DG. Characteristics of nebulisers used in the treatment of AIDS related Pneumocystis carinii pneumonia. $尹$ Aerosol Med 1988;1: 113-26.

9 O'Doherty MJ, Thomas SHL, Page C, Clarke AR, Mitchell D, Heduan E, et al. Does ${ }^{99 \mathrm{~m}} \mathrm{Tc}$ human serum 
albumin alter the characteristics of nebulised pentamidine isethionate? Nucl Med Commun 1989;10:523-9.

10 Sorenson JA, Phelps ME. Physics in nuclear medicine. New York: Grune and Stratton, 1980.

11 Macey DJ, Marshall R. Absolute quantitation of radiotracer uptake in the lungs using a gamma camera. $f$ Nucl Med 1982;23:731-5.

12 Fleming JS. A technique for the absolute measurement of activity using a gamma camera and computer. Phys Med Biol 1979;24:176-80.

13 Coates JE. Lung function throughout life: determinants and reference values. Lung function. Assessment and application in medicine. 4th ed. Oxford: Blackwell, 1979 $343,371-2$.

14 Forge NI, Mountford PJ, O'Doherty MJ, Coakley AJ. A comparison of quantification techniques in planar radionuclide imaging [abstract]. Nucl Med Commun 1991;12:296.
15 Alderson PO, Secher-Walker RH, Stominger DB, Markham BS, Hill RL. Pulmonary deposition of aerosols in children with cystic fibrosis. 7 Pediatr $1974 ; 84: 479-84$.

16 Wolfsdorf J, Swift DL, Avery ME. Mist therapy reconsidered; an evaluation of the respiratory deposition of labelled water aerosols produced by jet and ultrasonic nebulizers. Pediatrics 1969;43:799-808.

17 Lourenco RV, Loddenkemper R, Carton RW. Patterns of distribution and clearance of aerosols in patients with bronchiectasis. Am Rev Respir Dis 1972;106:857-66.

18 Thomas SHL, O'Doherty MJ, Graham A, Page CJ Nunan TO. Pulmonary deposition of nebulised amiloride in cystic fibrosis: comparison of two nebulisers. Thorax 1991;46:717-21.

19 Collis GG, Cole CH, Le Souef PN. Dilution of nebulised aerosols by air entrainment in children. Lancet 1990; 336:341-3. 